\title{
Exploring the limitations of an adult-led agenda for understanding the health behaviours of young people
}

\author{
W.J. Wills PhD RPHNutr, J.V. Appleton PhD RGN RHV PGCEA, J. Magnusson MSc and F. Brooks PhD \\ University of Hertfordshire, Hatfield, Hertfordshire, UK
}

\author{
Correspondence \\ Wendy Wills \\ CRIPACC \\ University of Hertfordshire \\ College Lane \\ Hatfield AL10 9AB, Hertfordshire, UK \\ E-mail:w.j.wills@herts.ac.uk
}

\begin{abstract}
Public health and health promotion agendas are usually determined by adults, even when the 'target' population is children and young people. Adult-centred frameworks for health maintenance and the promotion of well-being risk ignoring young people's conceptualizations and experiences of health and health-relevant behaviours. However, the current policy emphasis in the UK and elsewhere apparently seeks to position young people at the centre of their own health-related decisions. Building on the United Nations Convention on the Rights of the Child, this paper examines and critiques policies relating to young people in UK, European and worldwide contexts.

This paper then introduces data from two qualitative studies conducted in the UK. These studies illustrate that young people's definitions of health often run counter to prevailing public health and health promotion discourses. Young people do, however, often exhibit strategies for managing their health, even though they are frequently restricted by the perceptions that adults have about their lives and behaviour.

This paper argues that the new policy discourse is not yet being systematically turned into action to give all young people a voice. This is important to begin to understand young people's perspectives about what matters to them and what really influences their health behaviours.
\end{abstract}

Keywords: child-centred, children, health promotion, policy, young people

\section{Introduction}

International organizations promoting young people's health and welfare such as the United Nations Children's Fund, the World Health Organization and Save the Children increasingly acknowledge and promote the participation rights of young people (WHO 2002, Save the Children 2003). One of the most significant initiatives emphasizing the importance of young people's rights is the United Nations Convention on the Rights of the Child (UNCRC) (UN 1989). This international treaty has led to the increasing development of youth-friendly and youth-focused policies at a national level in many countries, and the right to participation is one of its key guiding principles (UNICEF 2007). Governments internationally have an obligation to create laws and policies which fully adhere to the principles of the convention.

The requirement to promote young people's participation in decisions affecting their lives is explicitly addressed in Article 12 (1) of the UNCRC which outlines:

States Parties shall assure to the child who is capable of forming his or her own views the right to express those views freely in all matters affecting the child, the views of the child being given due weight in accordance with the age and maturity of the child. The principle affirms that children are fully fledged persons who have the right to express their views in all matters affecting them and requires that those views be heard and given due weight in accordance with the child's age and maturity. It recognizes the potential of children to enrich decisionmaking processes, to share perspectives and to participate as citizens and actors of change. (UNICEF 2007, p. 1) 
In this paper, after a brief examination of some of the countries in the developed West which have taken up a youth-centred approach to policy-making, we discuss the potential motives of governments for putting 'young people first' in order to assess whether a paradigm shift towards youth centredness has, or is likely to, occur. The theoretical framework offered by the new social studies of childhood (James et al. 1998, James \& James 2004) is put forward to support the argument that exploring young people's everyday worlds and the meanings that young people themselves attach to their health-relevant behaviour offers adults an insight which is useful for building healthy public policies (WHO 1986). We then introduce findings from two qualitative studies carried out in the UK. These illustrate how young people's experiences and perceptions of their own health and health behaviours run counter to adult-led ager $\bar{\equiv}$ or health promotion and behaviour change, and how adult agendas often oppress youth, leading them to adopt strategies of resistance. We end by concluding that, while young people are able to accept an all-encompassing framework for health in line with the Ottawa Charter (WHO 1986), governments and policy-makers are somewhat further behind in this regard.

\section{Implementation of a youth-centred approach to health-relevant decision-making}

Across Europe, there is considerable commitment to recognizing young people's rights and involving young people in decision-making. Clark \& Percy-Smith (2006) argue that one of the key drivers in Europe for involving young people in participation activities has been the growth in service user involvement. Seeking the views of youth is recognised as a crucial part of public policy and practice development (Parton 2006a). The Nordic countries have set the 'gold standard' for youth participation in Europe as they have a long history of consulting and giving young people a voice in research and decisions that affect their lives (Warming 2006). Norway led the way in 1981 by establishing the world's first ombudsman for children to promote young people's rights. A young person's right to participate has become a central feature of Norwegian law and the Children Act (Skivenes \& Strandbu 2006). At 7 years of age, children have to be 'given an opportunity to express themselves', and at age 15 years 'they are recognized as parties in legal cases' and able to make their own decisions about their education and religious beliefs (Skivenes \& Strandbu 2006, p. 15).

Here in the UK, health and education are at the core of the UK's social inclusion agenda (Pugh \& Parton 2003). The Children Act was updated in 2004 , facilitating the inception of several new policies designed to give all young people better services and opportunities across health, education and social care, partly by empowering them and supporting young people to 'have their say'. Every Child Matters (Department for Education and Skills 2003, 2004) and a new National Service Framework for Children, Young People and Maternity Services (Department of Health 2004a) provided the agenda for change, plus Youth Matters (HM Government 2005, Department for Education and Skills 2006) which targets 14- to 19-year-olds specifically. Nineteen thousand young people gave the government their views about the services and opportunities they wanted to access during the Youth Matters public consultation - one of the largest responses by any one group to any government consultation (HM Government 2005). The UK policy review of children and young people (Department for Education and Skills 2007) asserts the long-term vision that 'every young person [should have] the ability to promote their personal development and make the most of their adolescent years' (Department for Education and Skills 2007, p. 38).

Within North America, the USA has not yet ratified the UNCRC (UN 1989), but there is evidence that America is adopting a youth-centred approach through the work of the National Collaboration for Youth, the Carnegie Corporation, the American Youth Policy Forum and a whole host of youth councils and youth engagement projects across the states. Consistent with the UNCRC, the Public Health Agency of Canada is adopting a youth-centred approach and trying to ensure that young people in Canada have opportunities to get involved in decisions about their personal development, as well as in wider policies and services (Caputo 1999, Public Health Agency of Canada 2007). In Australia, the Australian Association for the Welfare of Child Health is a national organization for parents, professionals and communities working together to ensure the emotional and social needs of young people, and their opinions are valued and recognised in the Australian Health Care System (AWCH 2007). In New Zealand, increasing attention is also being given to involving young people in decision-making through the work of the Ministry of Youth Development and the roll-out of the New Zealand Local Government Toolkit for Child and Youth Participation (Local Government New Zealand 2007).

\section{A paradigm shift in policies affecting young people?}

Within developed continents, then, it seems that many countries have taken steps to introduce policies designed, at least in theory, to put young people at the 
heart of the decisions and services which directly affect them. Williams wonders if this move towards a more youth-centred society signals a 'new, holistic, multidisciplinary approach to the professional care of children' (Williams 2004, p. 408) or does the new global policy agenda merely serve to reinforce adult-led discourses and perceptions about young people? There has been some criticisms of local government approaches for targeting either 'achievers' or 'troublemakers' to the exclusion of other groups of young people (Nairn et al. 2006). In the UK, the recent policy review of children and young people puts the emphasis on 'families caught in a low achievement cycle' and disabled children (Department for Education and Skills 2007), so universalism and egalitarianism are still some way off. Despite the rhetoric regarding the emphasis on a universal approach and youth participation, protection and surveillance discourses are at the heart of many government age $\equiv$ Parton 2006b). It may be unlikely, therefore, that a ground-breaking paradigm shift to youth centredness will fully materialise.

Skivenes \& Strandbu (2006, p. 11, emphasis added) argue that 'it is not sufficient that children are invited to participate and can express themselves. Consideration must be given to the ways in which states and adults view children to gain a proper understanding of their opinions, as well as ways in which adults can facilitate their participation.' In Australia (Graham et al. 2005, 2006), while children's participation rights are increasingly espoused in public policy contexts, there is often a gap between the rhetoric and what happens in practice. Participation rights are closely linked with notions of citizenship, yet recognition of these rights is variable across many levels of Australian society such as schools and communities (Harris 2006). It has been argued that young people themselves often have little understanding about their rights and responsibilities (Graham et al. 2005), although Caputo (2000) found that the concept of participation may have alternative meanings for different groups of young people. In the UK, while all recent policy developments act to support and empower young people to participate in decisions regarding their care and development, most policies relating to health give scant detail about how young people can participate to get their voices heard on an ongoing basis.

One barrier to young people's participation is that young citizens are conceptualised as 'future becomings', that is, the adults they will eventually become (Parton 2006b), with little motivation for listening to youth with a view to improving their lives for the benefit of their immediate health and well-being. A social investment strategy whereby governments feel they need to invest in youth to be 'repaid' at a later date by a cohort of economically conscientious, healthy, working adults
(Fawcett et al. 2004) perpetuates this situation and adds further weight to the notion that 'troublemakers' need extra intervention to ensure they reach their potential (i.e. their economic potential). This also helps explain why it is children, and not childhoods, that are valued under the new policy rhetoric (Williams 2004).

\section{Exploring young people's everyday worlds}

So, beyond adherence to the principles of the UNCRC, why is listening to, and acting on, youth perspectives important? The theoretical framework offered by the new social studies of childhood is useful in this sense (Christensen \& James 2000, James \& James 2004). Such an approach views young people as competent social actors capable of making sense of their own lives. They are considered to be stakeholders in decisions about their own health care needs and behaviour, and should be viewed as such, alongside parents, professionals and other adult stakeholders (Skivenes \& Strandbu 2006). Young people's behaviour, needs and attitudes are not the same as those of adults (that is not to say, however, that adults do not influence youth behaviour and attitudes). Young people are the embodiment of their own experiences (Mayall 1998). The meanings that young people assign to their own everyday healthrelevant behaviours as they resist the 'adult world' can therefore offer adults an important insight as to why young people do not always act in ways that adults approve of. This, by necessity, involves a rejection of the simplistic notion that youth lifestyles are problematic (Brooks \& Magnusson 2006) - 'risky behaviours' might only be seen as such, for example, when viewed from within an adult-focused deficit framework (Morgan \& Ziglio 2007). This approach also involves seeing young people as 'of their time', both as individuals and as affiliates of a specific cohort, as each generation of youth experiences particular social, economic and political contexts which are 'lived' and interpreted within a temporal framework (James et al. 1998). When adopting this framework, young people become accepted as 'beings' and not merely as 'adult becomings'.

\section{Data and participants}

In order to illustrate that there is often an uncomfortable fit between adult-led agendas and young people's own perspectives and experiences of health and healthrelevant behaviour, we will now draw on findings from two qualitative studies carried out with young people in schools, in areas of relative deprivation, in the UK. The first of these studies explored the dietary worlds of young teenagers (13-15 years) classified by their body mass index (BMI) as being 'normal' weight or 
overweight/obese. The second study aimed to explore the lived experiences of 14- to 15-year-olds who had defined themselves as being resistant to participating in physical education (PE) lessons at school, prior to a radical shift in PE provision. Full details of the methodology and study designs have been published elsewhere (Wills 2005, Brooks \& Magnusson 2006, Wills et al. 2006); therefore, only brief summaries are included here.

In the diet and obesity study (Wills 2005, Wills et al. $2005,2006)$, three schools in Scotland were selected and participants were recruited from Scottish school years S2 and S3 (students aged 13-15 years). Participants who lived in areas of relative socioeconomic deprivation were chosen for interview from those who completed a screening questionnaire, and had their height/weight measured (and BMI calculated). Thirty-six individual interviews were conducted with boys $(n=18)$ and girls $(n=18)$ who were of 'normal' weight $(n=18)$ or overweight/obese $(n=18)$. The International Obesity Taskforce cut-offs were used to classify young people by their BMI (Cole et al. 2000). Interviews were focused on young people's perceptions and experiences about food and eating, health, weight, body image and appearance. The interviews were transcribed and the data were analysed thematically and iteratively throughout the study. Findings from this research project (Wills 2005, Wills et al. 2006) will be used to show how young people's own perceptions of their health and weight run counter to policy and practice perspectives about diet, weight management and obesity in adolescence.

In the physical activity study (Brooks \& Magnusson 2006), the participating school was located in an area of high deprivation and poor-health status in the south-east of England. The school had recently undergone a major change in its approach to PE provision. A new PE programme had been developed in consultation with students, and included increasing the number and variety of activities that were offered and the amount of choice that students had over which activities to participate in. An active attempt was also made to change the PE culture from one of competitiveness to one of participation. Teachers felt that a significant change had occurred; most students did not wish to participate in $\mathrm{PE}$ at the start of the school year which decreased to three or four students not participating after the changes had been implemented (Brooks \& Magnusson 2006). Five focus groups were organised with 31 students in English school year 9 (students aged 14- 15 years); each student ( 25 girls and 6 boys) had self-identified as moving from being 'PE adverse' before the curriculum changes to 'PE active' after the changes were brought in. Participants volunteered to take part in focus groups, which were mixed gender and incorporated existing friendship networks. The focus groups concentrated on exploring young people's perceptions and experiences of PE before and after the modified PE programme was introduced. The focus group interviews were transcribed and analysed thematically, with particular attention paid to uncovering both individual and interactional themes. Findings will illustrate how, prior to the intervention taking place, adult agendas sometimes acted to restrict young people's behaviour. This prompted young people to resist this control and to find strategies to cope with adult perceptions about what they should or should not do during PE. Then, young people's perceptions of the impact of the intervention (Brooks \& Magnusson 2006) will be used to demonstrate how listening to young people and acting on their perceptions and experiences result in childfriendly practices which, ultimately, reflect policy goals.

\section{Ethical considerations}

Participants in both studies gave their own written consent, and parents were informed about the research. Ethical approval was received from the relevant local education departments (the diet/obesity study) and University of Hertfordshire ethics committee (the physical activity study). Pseudonyms are used throughout this paper to ensure anonymity.

\section{Young people's perceptions and experiences of their own health and health-relevant behaviour}

When the overweight and obese teenagers talked about their own bodies and body weight, there were many contradictions and much complexity (Wills et al. 2006). Much of what overweight/obese young people had to say about their bodies ran counter to both popular belief and much of the available literature (Williams \& Currie 2000). Most of the overweight/obese participants said they liked their bodies or parts of their body, and they were satisfied with their overall size or shape (Wills et al. 2006). Most did not view themselves as being overweight. Nicole, for example, who was BMI defined as obese, reported that she liked to look at herself now, as she did not consider that she was as fat as she had been previously:

Nicole: In primary school, I was as fat as anything; in first year [at secondary school], I was not bad, but now I feel ... for the last couple of years I was as podgy as anything, fat arms, and see now? When I look in the mirror at myself, ken (Scottish term meaning 'you know'), I used to hate looking in the mirror when I was fat, I used to hate looking in it, but now I look in it every day, my wee (little) favour.

Interviewer: Yeah? It makes you feel good?

Nicole: Aye (yes). (Aged 13; obese) (Wills et al. 2006) 
Many young people reported noticing how their bodies were constantly changing. Half of the teenagers who were BMI defined as being overweight/obese reported that their appetite had increased since leaving primary school or that their thighs, hips or stomachs got fatter, although puberty was rarely offered as an explanation for these changes (Wills et al. 2006). Most of the boys reporting weight gain since leaving primary school thought they would simply 'grow out of' their fatter bodies:

Interviewer: Has your shape or build changed as you've got older?

Liam: Yeah. I've been told I've been putting on weight because I'm gonna grow and my feet have grown about 5-and-a-half sizes since primary 7. (Aged 13; overweight) (Wills et al. 2006)

Many participating teenagers conceptualised their body shape with reference to the shape and size of members of their extended family (Wills et al. 2006). So, many thought there were some similarities between their build and that of specific, older members of their family who they had been told they resembled. Some of the teenagers who raised the issue of heredity seemed to be reassured by shared, familial body shapes, claiming that individual efforts to change were unlikely to be successful because of these similarities. There was a sense of fatalism about 'growing into' an already assigned, inherited body shape (Wills et al. 2006). Such perceptions are likely to influence feelings of efficacy regarding taking steps to change one's body or diet (Emslie et al. 2003).

Despite living in a culture that values thinness, many of the young people in the diet/obesity study said they were wary of friends or family members who expressed a desire to lose weight (Wills et al. 2006). We did not find a shared culture of dieting and weight loss among teenage friendship groups (Eisenberg et al. 2003). A general perception was that there was rarely a need for weight loss among the people the participants knew and that they should not feel pressured to lose weight. Rather than a fear of becoming fat (Sweeting \& West 2002), some young teenagers were alarmed by friends' talk of dieting or weight loss, because of a perceived risk of eating disorders and peers 'going anorexic'. Jodie's concern about her friend was typical of most participants:

Interviewer: Have you got friends your age that try and lose weight?

Jodie: Aye, well Fiona she used to be, I ... like there was nothing $\mathrm{o}^{\prime}$ her figure but she's got this new boyfriend and I think she's trying to lose weight, and she's really skinny. She used to be like, she went fae (from) like a [UK] size 12, now she's a size eight. And that was only like a couple of months.

Interviewer: Right, do you talk to her about it?
Jodie: I did say to her the last time I was there that I thought she had lost too much in a wee period of time but she said there was nothing to worry about. (Aged 14; obese) (Wills et al. 2006)

People from lower social class groups are thought to experience greater satisfaction with their overweight bodies than middle-class individuals (Wardle \& Griffith 2001). Without comparative data from young obese/overweight teenagers from different social groups, however, it is difficult to conclude how influential the lived experience of social class is for young people's perceptions of diet, weight and health. We did find, though, that many of the discourses voiced by these young people were mirrored in the narratives put forward by their parents and grandparents, who were interviewed in a companion study (Backett-Milburn et al. 2006). Parents are often unable to 'see' that their child is being overweight (Jeffrey et al. 2005) and do not link their child's weight status with their own (BackettMilburn et al. 2006).

This is not the first study to suggest that young people do not 'colonise the future' (Lawton 2002) and therefore have difficulty associating their current behaviour with their future health, but if working-class teenagers do not value thinness, and this is firmly grounded in their familial experience, then they are unlikely to aspire to having thinner bodies. This highlights that it is especially important that policy and practice initiatives aimed at reducing rates of obesity take account of youth experiences rather than reducing their behaviour to that of being 'risky' or deviant.

\section{Adult agendas and young people's strategies to resist control}

Before the PE curriculum and culture were modified, the young teenagers in the physical activity study were subject to rigid rules and expectations regarding what they could and could not do during PE lessons (Brooks \& Magnusson 2006). Participants said they had little choice over what activities they could take part in, there was no flexibility over the PE uniform they were expected to wear and there were strict rules about showering at the end of a lesson. The showering was perceived as problematic by the students (girls in particular) as the facilities were not very pleasant, and there were no shower curtains, which made some students feel uncomfortable. One female participant, Sue, explained:

Sue: The previous teacher would come and check that we were in our towels and make us line up and touch our hair to see if it was wet. So, we used to just flick water on our hair. (Brooks \& Magnusson 2006) 
The UK government agendas state the usefulness of sports for instilling values of discipline and responsibility in young people (DCMS 2000). However, the findings from the focus groups showed that teenagers who were reluctant to participate in PE under adult-led restrictions developed strategies to resist any involvement in the lesson. This included 'forgetting' to bring their PE uniforms to school, and bringing in notes to say they could not participate because of illness, or, for girls, because of menstruation, as well as an outright refusal to take part in activities. In this way, young people who resisted participation in PE because of the constraints set on them by adult-imposed rules and decisions were in a sense forced to present themselves as 'not well enough' to participate in physical activity (Brooks \& Magnusson 2006).

Interviewer: What would you be doing if things hadn't changed?

Angie: Nothing. I would have had a permanent verruca (foot wart).

Paul: Yes (laughing). That is what I was going to say. I had letters for a verruca all the time. People used to go round asking if any one in the class would write it for them. Remember that? (to girl).

Melanie: Yeah! My mom used to write period letters for me. She thought it was awful as well that we had to wear those skirts and shower.

Stephanie: Yeah, mine did too, periods every week! (Brooks \& Magnusson 2006)

The finding that girls in particular are critical of traditional PE uniforms (which often consist of revealing shorts or skirts) is not new and has been reiterated by several other studies (Coakley \& White 1992, Flintoff \& Scraton 2001, Rees et al. 2001). Despite this overwhelming evidence that the PE uniform by itself acts as a barrier to many adolescent girls' participation in PE, little progress appears to have been made regarding implementing any wide-reaching change in this area. In the physical activity study presented here (Brooks \& Magnusson 2006), the students spoke about the change to the PE uniform as one of the positive outcomes of the intervention:

Interviewer: So, then Ms Falk (PE teacher) arrived and things changed, what changed?

Casey: The uniform.

Sue: Straight-away (laughs).

Interviewer: Was that a big thing?

Casey: It was like within a term, it had changed and we were all like 'oh, thanks' (laughs).

Many of the students spoke of the limitation in choice of activities in school sports and PE as a barrier to their participation. Under the old PE curriculum, activities had been decided on by the PE teachers, and students themselves had no influence over what types of activities they were to take part in. However, some of the students had used their strategies of resistance to actively lobby for a change in activities, and to negotiate additional options. This was very visible when talking to a group of young people who all did dance, but who were not interested in other forms of activity:

Interviewer: When this dance group started, was it something that you said that you really wanted at the school or was it just something that ...?

Yvonne: We made them have it.

Lisa: We protested for it (laughs). There was options that we didn't want to do, it was like badminton and weights or trampolining and we said 'can we do dance' and the teachers were like 'well it's not an option' and we were like going 'we're not moving until we can do dance...'

Once the students perceived they had increasing control and more of a say in the PE curriculum, they also stated that the atmosphere shifted from being about performing to adult-set standards and achieving excellence in PE and sport, to being much more inclusive, friendly and rewarding. The changes extended to the attitudes of the PE staff who were now seen to be much more encouraging towards students of all abilities; they praised effort and participation regardless of achievement and excellence.

Interviewer: Why is it [PE] great?

Laura: Because all the teachers are just really friendly and they treat you like with respect and everything and they make it fun.

Interviewer: What do you mean by respect?

Laura: Well, they don't look down on you because you're a student, they're like ... like our dance teacher, she's like our friend as well as our teacher, she treats us as friends as well as her students so she joins in with us and everything.

Interviewer: And that's different to what it was before?

Laura: Yeah.

Shifting the focus of PE away from achieving sporting excellence might be seen as going against the aims of the UK government, whose agenda for greater participation in PE and school sport would appear to be strongly geared towards producing greater international success for British athletes (DCMS 2000). However, this shift away from a focus on adult-set goals for PE and school sport (e.g. success at competitions, winning teams) that had previously marginalised a large proportion of students who did not fit into this category, to one that valued young people's individual efforts, proved to be beneficial to student's emotional well-being in ways 
that crossed-over into areas other than physical activity (Brooks \& Magnusson 2006):

Karen: Like in our PE lessons before, like us lot used to be pretty quiet and we'd just like stay out of it but since like Jenny's [PE teacher] come here we've been more confident in what we do.

Yvonne: Yeah, she can't shut us up now!

Karen: They give you confidence, 'cause they make you believe in yourself. (Brooks \& Magnusson 2006)

\section{Discussion and conclusion}

Countries in the developed Western world increasingly espouse the adoption and delivery of youth-led policies. In particular, this is much in evidence in the UK where giving children and young people their voice (finding out what young people want) is increasingly regarded as a legitimate response to help combat health inequalities, class inequalities, deprivation and disadvantage, and tackle social exclusion and the increasingly reported 'social problems'. Yet, whether young people's views about their own health and health-relevant behaviour really take centre stage (i.e. any more than a tokenistic gesture) is open to question. There are two issues here regarding adult-led agendas that require attention - that young people are frequently still not seen as expert actors whose opinions are worth eliciting, despite the evidence that many youth have much to offer and, second, that when young people are given the opportunity to participate, adults still seem to find it hard to listen to or act on what they have to say. Both issues serve to oppress and disempower young people, not least when adults take their continued failure to 'comply' as evidence for further adult-led action.

There is a tendency for governments to encourage participation when new policy agendas are being developed, but then to ignore young people's views the rest of the time. Policies which span the life-course, for example, in the UK context, Choosing Health (Department of Health 2004b, 2006) and the National Institute for Health and Clinical Excellence (NICE) clinical guidelines for the management of obesity in adults and children (NICE 2006), are, however, less likely than specifically youth-centred policies to incorporate the views of young people during their design and implementation. The result is often poorly researched recommendations which do not resonate with young people's experiences. For example, the findings reported here show that many overweight/obese teenagers do not engage with current public health discourses about 'fatter bodies', not because they are ignorant of the 'facts' about obesity, but because their everyday, embodied experiences tell them that their body shape 'fits in' with the bodies of their peers and family and they do not feel 'ill' (Wills 2005, Wills et al. 2006). The NICE obesity guidelines take no account of such social definitions of obesity (nor do they offer specific guidance that older children themselves can access). More worrying is when such apparently 'deviant' behaviour subsequently defines a family as being 'at risk' and in need of state intervention, but there is little scope for agencies to truly engage with the 'problem' and help to find a solution.

It has been suggested that the intense focus on improving physical health through monitoring children's weight, promoting healthy eating choices and increased physical activity prevents initiatives being conceptualised that regard children as social actors which thereby impoverishes existing health promotion strategies and PE curricula (Burrows \& Wright 2007). In contrast, the findings presented from the physical activity study illustrate the positive benefits that can be gained by giving young people some control over their own behaviour and focusing on their agendas, as well as the power that must be relinquished by adults in order to achieve this (Brooks \& Magnusson 2006). This type of partnership intervention with young people is not widespread, but needs to become more prevalent for a paradigm shift to youth centredness to occur.

The emphasis on sports in schools indicates an expectation of positive impact on young people that goes beyond good health and sporting achievement. It suggests that PE may also help to mould young people into 'good citizens' by fostering discipline and responsibility, and minimizing undesirable behaviour. The PE curriculum in the UK is shaped by government agendas that seek to increase the profile of British athletes in international sporting events (DCMS 2000). Traditional sports, those that have the chance of leading to international prominence (e.g. through the Olympics or World Cups), are also typically those that are promoted within a traditional adult-led PE curriculum. Choices that are popular with young people (and with girls in particular), such as dance and trampolining, do not have high-profile equivalents, and as such may be considered of little value by adults. Paradoxically, this blinkered focus on achievement and excellence in sports is likely to limit the chances of athletic success as some children, who may not benefit from the traditional model of PE provision, 'opt out' of sport altogether. In contrast, the physical activity study presented here illustrated that by putting the focus on inclusion and empowerment, many young people developed an interest in physical activity that had not previously been there (Brooks \& Magnusson 2006). Initiatives of the kind described in the physical activity study also illustrate the way that young people's agendas give primacy to a 
wider range of issues other than just physical health (Brooks \& Magnusson 2007). The emphasis young people may place on emotional well-being further serves to highlight the limitations and potential ineffectiveness of adult-led health promotion agendas that prioritises risks to physical health and, in particular, future physical health.

The Ottawa health promotion charter (WHO 1986) emphasises that health promotion 'goes beyond healthy lifestyles to well-being'. It seems that while many young people appear to be orientated towards such an understanding in relation to their health behaviour, the surrounding adult world, with its emphasis on surveillance and risk in relation to young people, still needs to catch up.

\section{Acknowledgements}

The diet/obesity study was funded by the Research Unit in Health, Behaviour and Change at the University of Edinburgh, and NHS Health Scotland. The physical activity study was funded by HertNet (Hertfordshire Primary Care Research Network Consortium). The opinions expressed in this paper are those of the authors, and not of the funding bodies. Details of the diet/obesity and physical activity studies are reprinted here with permission from Elsevier and Oxford University Press respectively.

\section{References}

AWCH (2007) Making a difference for kids [WWW document]. URL http://www.awch.org.au

Backett-Milburn K., Wills W.J., Gregory S. \& Lawton J. (2006) Making sense of eating, weight and risk in the early teenage years: views and concerns of parents in poorer socioeconomic circumstances. Social Science \& Medicine 63 (3), 624-635.

Brooks F. \& Magnusson J. (2006) Taking part counts: adolescents' experiences of the transition from inactivity to active participation in school-based physical education. Health Education Research 21 (6), 872-883.

Brooks F. \& Magnusson J. (2007) Physical activity as leisure: the meaning of physical activity for the health and well-being of adolescent women. Health Care for Women International: Special Edition, Health and Leisure 28 (1), 69-87.

Burrows L. \& Wright J. (2007) Prescribing practices: shaping healthy children in schools. International Journal of Children's Rights 15, 83-98.

Caputo T. (1999) Voices of Youth. A Review of Research and Consultation Documents. Childhood and Youth Division Health Canada, Ottawa.

Caputo T. (2000) Hearing the Voices of Youth. Youth Participation in Selected Canadian Municipalities. Childhood and Youth Division Health Canada, Ottawa.

Christensen P. \& James A. (Eds) (2000) Research with Children: Perspectives and Practices. Falmer Press, London.

Clark A. \& Percy-Smith B. (2006) Beyond consultation: par- ticipatory practices in everyday spaces. Children, Youth and Environments 16 (2), 1-9.

Coakley J. \& White A. (1992) Making decisions: gender and sport participation among British adolescents. Sociology of Sport Journal 9, 20-35.

Cole T., Bellizzi M., Flegal K. \& Dietz W. (2000) Establishing a standard definition for child overweight and obesity worldwide: international survey. British Medical Journal 320, $1-6$.

DCMS (2000) A Sporting Future for All. Department for Culture, Media and Sport, London.

Department for Education and Skills (2003) Every Child Matters: Change for Children. The Stationery Office (TSO), London.

Department of Health (2004a). National Service Framework for Children, Young People and Maternity Services: Core Standards. Department of Health, London.

Department of Health (2004b) Choosing Health: Making Healthier Chooses Easier. Department of Health, London.

Department of Health (2006) Health Challenge England - Next Steps for Choosing Health. Department of Health, London.

DfES (2004) Every Child Matters: Next Steps. Department for Education and Skills, London.

DfES (2006) Every Youth Matters: Next Steps. Department for Education and Skills, London.

DfES (2007) Policy Review of Children and Young People. Department for Education and Skills, London.

Eisenberg M., Neumark-Sztainer D. \& Story M. (2003) Associations of weight-based teasing and emotional wellbeing among adolescents. Archives of Pediatrics $\mathcal{E}$ Adolescent Medicine 157, 733-738.

Emslie C., Hunt K. \& Watt G. (2003) A chip off the old block? Lay understandings of inheritance among men and women in mid-life. Public Understanding of Science 12, 47-65.

Fawcett B., Featherstone B. \& Goddard J. (2004) Contemporary Child Care Policy and Practice. Palgrave, Basingstoke.

Flintoff A. \& Scraton S. (2001) Stepping into active leisure? Young women's perceptions of active lifestyles and their experiences of school physical education. Sport, Education and Society 6 (1), 5-21.

Graham A., Shipway B., Fitzgerald R. \& Whelan J. (2005) Children and Young People's Perspectives on Rights, Responsibilities, and Citizenship in Australia. Centre for Children and Young People, Southern Cross University, Lismore, New South Wales, Australia.

Graham A., Whelan J. \& Fitzgerald R. (2006) Progressing participation: taming the space between rhetoric and reality. Children, Youth and Environments 16 (2), 231-247.

Harris A. (2006) Introduction: critical perspectives on child and youth participation in Australia and New Zealand/ Aotearoa. Children, Youth and Environments 16 (2), 220-230.

HM Government (2005) Every Youth Matters. HM Government, London.

James A. \& James A.L. (2004) Constructing Childhoood: Theory, Policy and Social Practice. Palgrave, London.

James A., Jenks C. \& Prout A. (1998) Theorizing Childhood. Polity Press, Cambridge.

Jeffrey A.N., Voss L.D., Metcalf B.S., Alba S. \& Wilkin T.J. (2005) Parents' awareness of overweight in themselves and their children: cross sectional study within a cohort (EarlyBird 21). British Medical Journal 330, 23-24.

Lawton J. (2002) Colonising the future: temporal perceptions and health-relevant behaviours across the adult lifecourse. Sociology of Health E Illness 24 (6), 714-783. 
Local Government New Zealand (2007) The New Zealand local government toolkit for child and youth participation [WWW document]. URL http://www.myd.govt.nz/Youthparticipation/childrenstoolkit/childrenstoolkit.asp

Mayall B. (1998) Towards a sociology of child health. Sociology of Health E Illness 20 (3), 269-288.

Morgan A. \& Ziglio E. (2007) Revitalising the evidence base for public health: an assets model. Promotion $\mathcal{E}$ Education 14 (Suppl 2), 17-22.

Nairn K., Sligo J. \& Freeman C. (2006) Polarizing participation in local government: which young people are included and excluded? Children, Youth and Environments 16 (2), 248-273.

NICE (2006) Guidance on the Prevention, Identification, Assessment and Management of Overweight and Obesity in Adults and Children. National Institute for Health and Clinical Excellence Clinical Guideline 43. National Institute for Health and Clinical Excellence, London.

Parton N. (2006a) Safeguarding Childhood: Early Intervention and Surveillance in a Late Modern Society. Palgrave Macmillan, Basingstoke.

Parton N. (2006b) 'Every Child Matters': the shift to prevention whilst strengthening protection in children's services in England. Children and Youth Services Review 28 (8), 976-992.

Public Health Agency of Canada (2007) Childhood and adolescence [WWW document]. URL http:/ / www.phac-aspc.gc.ca/ dcq-deq/main_e.html (last accessed 4 December 2007).

Pugh G. \& Parton N. (2003) New Labour Policy and its outcomes for children: introduction. Children $\mathcal{E}$ Society 17 (3), 157-161.

Rees R., Harden A., Shepherd J., Brunton G., Oliver S. \& Oakley A. (2001) Young People and Physical Activity: A Systematic Review of Research on Barriers and Facilitators. EPPICentre, Social Science Research Unit, Institute of Education, University of London, London.

Save the Children (2003) So You Want to Consult with Children? A Toolkit of Good Practice. International Save the Children Alliance, London.

Skivenes M. \& Strandbu A. (2006) A child perspective and children's participation. Children, Youth and Environments 16 (2), 10-27.
Sweeting H. \& West P. (2002) Gender differences in weight related concerns in early to late adolescence. Journal of Epidemiology \& Community Health 56, 700-701.

UN (1989) United Nations Convention on the Rights of the Child. Office of the United Nations High Commissioner for Human Rights, Geneva.

UNICEF (2007) Fact sheet: the right to participation [WWW document]. URL http://www.unicef.org/crc/files/Rightto-Participation.pdf

Wardle J. \& Griffith J. (2001) Socioeconomic status and weight control practices in British adults. Journal of Epidemiology $\mathcal{E}$ Community Health 55, 185-190.

Warming H. (2006) 'How can you know? You're not a foster child': dilemmas and possibilities of giving voice to children in Foster Care. Children, Youth and Environments 16 (2), 28 50.

WHO (1986) Ottawa Charter for Health Promotion. World Health Organisation/HPR/HEP/95.1, Ottawa.

WHO (2002) Adolescent Friendly Health Services - an Agenda for Change. World Health Organization, Geneva.

Williams F. (2004) What matters is who works: why every child matters to new labour. Commentary on the DfES Green Paper Every Child Matters. Critical Social Policy 24 (3), 406-427.

Williams J. \& Currie C. (2000) Self-esteem and physical development in early adolescence: pubertal timing and body image. Journal of Early Adolescence 20 (2), 129-149.

Wills W.J. (2005) Food, Eating, Health and Fatness: The Perceptions and Experiences of Young Teenagers from Disadvantanged Families. Research Findings Issue 8. RUHBC, University of Edinburgh, Edinburgh.

Wills W.J., Backett-Milburn K., Gregory S. \& Lawton J. (2005) The influence of the secondary school setting on the food practices of young teenagers from disadvantaged backgrounds in Scotland. Health Education Research 20 (4), 458-465.

Wills W.J., Backett-Milburn K., Gregory S. \& Lawton J. (2006) 'Young teenagers' perceptions of their own and others' bodies: a qualitative study of obese, overweight and 'normal' weight young people in Scotland. Social Science $\mathcal{E}$ Medicine 62 (2), 396-406. 